\title{
COESÃO SOCIAL E EVASÃO EM ASSENTAMENTOS RURAIS NO EXTREMO-SUL DO BRASIL
}

\author{
Paulo Freire Mello
}

\begin{abstract}
Através de etnografias realizadas em dois assentamentos no Rio Grande do Sul, discute-se os processos de coesão social interna e sua potencialidade em estancar a evasão e a rotatividade dos assentados. A adoção da perspectiva da sociologia da crítica de Boltanski, em associação com aportes pontuais de Bourdieu, Wolf e Elias, permitiu compreender os processos de mobilidade e de construção da coesão social dos assentados. Essa última é relacionada à reciprocidade, em especial ao parentesco e às relações religiosas e de vizinhança. Verificou-se que os assentados, cada vez mais situados na "cidade doméstica", estão construindo processos corporativos, ainda que de forma negociada com o MST, INCRA e vizinhança. Não se encontrou correlação entre a evasão e diversas variáveis relacionadas à dimensão material nos 193 assentamentos pesquisados.

PALAVRAS-CHAVE: rotatividade, reforma agrária, reciprocidade, sociologia da crítica, religião.
\end{abstract}

\section{INTRODUÇÃO}

Oobjetivo deste artigo édiscutir a rotatividade dos assentados de reforma agrária em relação aos processos internos de coesão social, com base na sociologia da crítica, ainda que combinada a outras perspectivas teóricas. O termo evasão caracteriza a fuga ou o desenquadramento dessas famílias da política de reforma agrária, enquanto as trocas e abandono de lotes irregulares (ou seja, nãoassentados oficialmente perante o Instituto Nacional de Colonial e Reforma Agrária - INCRA) demonstram a mobilidade dentro ou à margem da reforma agrária.

Os assentamentos escolhidos para a realização do estudo foram o Apolo e o Santo Ângelo, ambos em Santana do Livramento (RS), município que apresenta a maior concentração de assentamentos no Rio Grande do Sul. Embora com eva-

* Mestre e Doutorando em Desenvolvimento Rural PGDR/UFRGS. Engenheiro agrônomo do INCRA-RS.

Av. Loureiro da Silva, 515, Centro. Cep: 90.010-420. Porto Alegre - Rio Grande do Sul - Brasil. pfreiremello@yahoo.com.br sões distintas, os assentamentos escolhidos para a realização do estudo foram criados no mesmo ano e contemplados com políticas públicas muito semelhantes, além de integrarem um público oriundo do mesmo acampamento.

Um estudo sobre rotatividade em assentamentos rurais do Rio Grande do Sul (Mello, 2006) constata um índice médio de evasão de $22 \%$, para um universo total de 193 assentamentos pesquisados. As taxas de evasão encontradas neste estudo foram correlacionadas a um conjunto de variáveis, como tempo de acesso a linhas de crédito, percentual de lotes com tipos diversos de infraestrutura, qualidade dos solos, tipo de assistência técnica utilizada, executor do assentamento, ano de implantação, tipo do público e região de implantação. A falta de correlação do fenômeno da evasão com essas variáveis (exceto o ano de implantação e a região) nos impeliu a prospectar outros condicionantes qualitativos do fenômeno. Procuramos compreender como se davam as relações sociais dentro de assentamentos, no sentido de interpretar como o padrão de coesão social no seu interior pode ou não ter relação com os processos de evasão. As 
duas etnografias realizadas neste estudo permitiram confirmar a hipótese que a coesão social tende a estancar a evasão.

A mobilidade dos assentados não se restringe apenas aos processos de evasão. Observamos que outros acontecimentos têm influência relevante sobre a evasão, tais como mortes, trocas ou mesmo abandono de lotes ocupados irregularmente, o que nos levou a alargar a análise para compreender o fenômeno maior da rotatividade, abarcando todas essas situações. Para a consecução da etnografia, efetuaram-se entrevistas aleatórias direcionadas à pessoas que possuíam uma posição diferenciada no assentamento, a exemplo de lideranças políticas e religiosas. A partir de questionários semiestruturados, realizamos um total de quarenta e duas entrevistas, com trinta e dois assentados, quatro técnicos do INCRA, duas lideranças do Movimento dos Trabalhadores Sem-Terra (MST), um pastor evangélico e três técnicos da Cooperativa de Prestação de Serviços Técnicos Ltda (COPTEC). ${ }^{1}$ A compilação dos dados nos permitiu localizar os assentados com relação ao tipo de terreno que cada um ocupava, se na área seca ou em área afetada por alagamento.

\section{OS MUNDOS DE JUSTIÇA EM AÇÃO NA REFORMA AGRÁRIA}

Na década de 1970, Bourdieu (2000) percebeu que o celibato, entre os camponeses da França, era, de forma ambivalente, estimulado pelas famílias devido à falta de mulheres no campo, já que elas eram - assim como os irmãos mais novos, também não herdeiros de terra - as primeiras a emigrar ou a preferir os citadinos nos mercados matrimoniais. Esse fenômeno se dava no bojo de um processo maior, de dominação simbólica do mundo urbano, para além da dominação econômica e do mercado, consubstanciando-se numa força de atração para as cidades. A emigração para as cidades, especialmente de mulheres (fugindo

${ }^{1}$ Cooperativa de técnicos ligada ao MST, que atende os dois assentamentos. da tirania patriarcal), é também fruto da unificação do mercado de bens simbólicos e econômicos. $\mathrm{O}$ rompimento daquele isolamento parcial dos camponeses (chamado pelo autor de localocentrismo), que permitia uma resistência à cidade, e o consequente desaparecimento dos valores camponeses, vistos, a partir daí, como inferiores, explicitam a crise do modo de vida camponês. Esse fenômeno apresenta certa homologia com a realidade brasileira e com o caso em estudo.

O processo de individualização na modernidade, descrito por Elias (1994), caracteriza-se pelo declínio do que o autor chamou de identidade "nós", que tinha papel central nas sociedades antigas, diante da identidade "eu", surgida no Renascimento. O que não significa ausência de conflito, mas que sobreviviam somente os grupos que conseguiam alcançar a um modus vivendi com certo equilíbrio entre a cooperação e o conflito. Tal processo se caracterizou pelo enfraquecimento das corporações, especialmente as relacionadas ao parentesco.

Aqui parece se configurar uma importante meta para o desenvolvimento dos assentamentos, ao nos darmos conta de que, mais do que uma questão econômica, a busca de um equilíbrio na sociabilidade parece ser crucial em locais conflituosos, como costumam ser os assentamentos. Em outras palavras, nos assentamento, à medida que a balança identitária pende para o "nós", a perspectiva é o alcance de maior estabilidade e, com isso, uma menor evasão. Todavia adotar a idéia que aponta para a centralidade de valores tradicionais entre os assentados, como uma possível resistência do "mundo tradicional", não vem no sentido de substancializar "o moderno e o arcaico", mas sim de compreender o processo social de forma relacional e interdependente.

Como os assentados, diante do processo cada vez maior de atração urbana, conseguem construir laços sociais que minimizam a evasão? É, pois, na noção de reciprocidade que encontramos os mecanismos de sua construção. Ela é entendida aqui, conforme Sabourin (2004), como o ato de dar, receber e retribuir dádivas, de forma, ao mesmo tem- 
po, interessada e desinteressada, porém, reversível. Estudos antropológicos perceberam que todas as sociedades humanas trocam presentes, e essas trocas permitem não só viabilizar necessidades econômicas e sexuais (no caso de trocas de mulheres, origem do parentesco, segundo Levi Strauss), mas também estabelecer alianças políticas e coesão social, através da (re) produção de valores humanos, tais como amizade, responsabilidade, confiança, justiça, reputação, etc, conforme refere Sabourin (2005). Mesmo reconhecendo que a reciprocidade nem sempre assume facetas positivas, procuramos perceber como os agentes sociais constroem (ou não) possibilidades de convivência e evitam conflitos.

Polanyi (2000) identificou reciprocidade e intercâmbio como noções diferentes, no que tange aos códigos morais de um sistema de valores. Para ele, a reciprocidade era um elemento formador de relações sociais nas sociedades tradicionais. Com o fim dessas civilizações, o autor previu o término da reciprocidade e o advento do intercâmbio capitalista. Para Sabourin (2004) a reciprocidade é a reprodução da dádiva numa relação reversível entre sujeitos, enquanto o intercâmbio é apenas uma permuta de objetos, ainda que consideremos essas duas categorias como modelos ideais que convivem na vida real. Embora com perspectivas diferentes, autores como Mauss, Levi-Strauss, Bourdieu e Caillé (2002) concordaram que a reciprocidade promove o laço social e a própria idéia de aliança.

Consideramos que a reciprocidade, embora venha, por um lado, perdendo espaço para o intercâmbio mercantil, por outro, ainda mantém uma participação importante, com seus valores e práticas, como constata Sabourin (2005), em algumas comunidades rurais brasileiras. Mas nem toda reciprocidade é positiva; há relações de reciprocidade assimétricas, do tipo relação patrono-cliente (Wolf, 2003), que podem (assim como as rivalidades criminosas, como veremos num dos casos), ao contrário do proposto acima, prejudicar a formação de laços sociais, seja pelo desincentivo à reciprocidade positiva ou por gerar conflito e medo.
Uma análise dos resultados da reciprocidade entre os camponeses pode ser encontrada na obra de Wolf (2003), cujo conceito de comunidade corporada fechada, construído a partir de estudos com camponeses sul-americanos, revelou que, nas comunidades observadas, gerou-se uma estrutura comunitária coesa e normatizada, com sistema de poder fortemente ligado à religião e ligando-se ao mundo externo, muitas vezes, mediante relações de reciprocidade assimétrica, no caso, a patronagem. Cientes de que não temos como transportar tal conceito integralmente para a nossa discussão, utilizamos a noção de comunidade corporada, sem buscar sua substancialização, e sim nos ater à idéia de corporação, como sugere Woortmann (1995), calcada, fundamentalmente, no parentesco, como sua espinha dorsal. Para a autora (corroborada por Martins, 2003), o parentesco e a reciprocidade são componentes centrais em todas as formações camponesas ocidentais, fato constatado em nossas etnografias.

Um exemplo dos efeitos da coesão social foi apresentado por Elias e Scotson (2000), demonstrando como pessoas de um grupo eram estigmatizadas e hostilizadas (outsiders) por pessoas de outro grupo (estabelecidos), da mesma etnia e classe social, somente por serem mais novas e, portanto, menos relacionadas, na localidade. Os mais antigos se sentiam ameaçados no seu estilo de vida e reagiam com intolerância. Movidos por uma necessidade de ampliar a sua auto-estima, o faziam através da inferiorização do outro grupo. O elemento-chave era uma menor coesão social do grupo mais novo, que tinha laços menos sólidos, por conta da recente imigração e do próprio estigma que eles incorporavam. Situações como essa são recorrentes em assentamentos, incluindo os estudados aqui, de modo que a evasão foi compreendida melhor a partir da identificação desses grupos e de suas relações, inclusive com a observância do papel desempenhado pelos mediadores na potencialização ou contenção de processos de estigmatização.

Nos dois assentamentos estudados, constatamos uma grande importância da religião na 
vivência dos assentados, inclusive como forma de revitalização das relações de reciprocidade. Os evangélicos (aqui representados pela Assembléia de Deus), significam um elemento moral e organizativo relevante e novo, que influencia na reconfiguração das relações sociais nos assentamentos, muitas vezes em oposição ao MST, organização política hegemônica no espaço social relacionado a assentamentos no estado do Rio grande do Sul.

Para Durkheim, a religião cria e administra o mundo do sagrado, sinalizando o laço social necessário para uma vida social sem anomia, como dimensão ética (Sanchis, 2003). Wolf (1976), ressaltou a função utilitária e moral da religião para sustentar e equilibrar o ecossistema camponês e sua organização social, constituindo-se num componente da ordem ideológica mais ampla. Nos casos em estudo, a ascensão evangélica parece se valer de certa disposição social dos camponeses, fruto das contingências locais, ao mesmo tempo em que é parte do processo maior de pentecostalização da sociedade brasileira, especialmente entre as classes mais empobrecidas, como apontou Mariano (2005). A ascensão dos pentecostais parece ocorrer, fundamentalmente, pela sua eficácia na contenção do alcoolismo e, consequentemente, da violência.

Para a consecução da análise etnográfica, enfocamos a vertente da sociologia chamada sociologia da crítica, de onde extraímos alguns fundamentos epistemológicos, sem abandonar, contudo, as perspectivas apresentadas até aqui, pois são passíveis de uma utilização mais pontual. Autores como Levi-Strauss e Bourdieu, embora de diferentes perspectivas, adotam a postura epistemológica do desvelamento, isto é, a idéia de que o sociólogo deve explicitar os reais e ocultos interesses e motivos das ações dos atores sociais, delineando uma sociologia crítica. Essa postura foi duramente criticada por Boltanski (1990), com a assertiva de que a sociologia crítica induz o sociólogo a julgar-se capaz de um esclarecimento superior, em que a verdade é alcançada porque ele assume uma exterioridade, liberando-se dos interesses em luta. Para o autor, esse "lugar exterior", juntamente com o instrumental metodológico, é o "la- boratório". Fora do "laboratório", ele é um ator como os outros. Para manter essa postura, ele deve fazer um sacrifício e renunciar à ilusão dos atores, para desvelar a realidade. A "ilusão dos atores" aparece aqui como a garantidora da ordem social, na medida em que se apresenta como desinteresse.

A sociologia estudou a religião com essa perspectiva de torná-la menos ilusória para o homem moderno (estudos nessa direção vieram sempre conectados às teorias da modernidade), salvando a moral necessária à ordem e refundando a religião numa perspectiva laica. Para ela, tudo é crença, e só o laboratório desvela. Dessa forma, o sociólogo reivindica sua autoridade da ciência e sua utilidade social. Porém, ele também pode ser desvelado em suas ilusões, interesses e ideologias. A crítica de Boltanski (1990) é que essa sociologia não foi até o fim e não esclareceu qual a sua posição. Fixou o recorte, proposto por Weber, entre fatos e valores, mantendo-se, aparentemente, ao abrigo da crítica. Entretanto, a competência para julgar não é o apanágio dos sociólogos e dos filósofos.

Boltanski (1990) propôs que a sociologia capte a construção das causas que justificam as ações dos agentes, mas sem renunciar à assimetria entre o pesquisador e os atores, nem ao laboratório. Pelo contrário, deve adotar uma exterioridade ainda mais elevada. A tarefa do sociólogo é "reconstruir da forma mais completa possível, o espaço crítico no interior do qual o negócio se matiza e se joga”. Deve atentar para o discurso (mesmo que nem tudo esteja no discurso) e realizar um relatório conclusivo dos relatos.

Latour (1994) realizou uma dura crítica aos pensadores modernos, na sua dissociação, para ele fictícia, entre discurso político e científico, que inventa o mundo moderno. De um lado, temos o Leviatã, feito somente de relações sociais; de outro, a Ciência e o laboratório, onde os cientistas traduzem a fala da natureza. Tal dicotomia (falsa, segundo o autor) nos permite o ato da crítica, do desvelamento, e o próprio “crescimento científico". Esse afã de criticar, Latour o encara como uma "raiva", cuja vacina antirábica é apresentada por Boltanski e Thévenot, com a sociologia da crítica (Latour, 1994, p. 48). 
O autor nos alertou para um tempo que não passa, em que os arcaísmos que julgamos superar (o tempo das confusões entre natureza e cultura) rondam nossa existência, e aquelas manifestações tidas como superadas (tais como a reciprocidade, diríamos) passam a ser vistas como algo não só presente, quanto relevante. Por isso, afirma que, na verdade, somos não-modernos, pois não podemos compreender o mundo se dissociamos realmente sociedade e natureza, já que os laços sociais não se sustentam sem os objetos. Sendo assim, não há desencantamento algum a ser feito, pois não há como purificar a sociedade da natureza e vice-versa. O que há são híbridos, ou quase-objetos, que precisam ser compreendidos na forma de redes. Dodier (1993), valendo-se de três obras de Boltanski e Thévenot, propõe a

... possibilidade de ver as ações humanas como uma série de sequências onde as pessoas, engajadas em momentos sucessivos, devem viabilizar competências diversas a fim de realizar, de acordo com as circunstâncias, uma adequação à situação presente (Dodier, 1993, p. 77).

O ponto de partida refere-se às disputas por justiça. Nessa "teoria dos mundos de ação", os atores apoiam-se em diferentes princípios de justificação para argumentar seus pontos-de-vista e buscar acordos. Esses princípios formam o que os autores chamaram de "cidades" (um mundo comum relacionado a princípios de justiça), das quais descrevem seis modelos (cidade inspirada, da opinião, cívica, mercantil, industrial e doméstica):

Cada modelo é a transposição de uma obra maior da filosofia política que conseguiu expor com clareza as bases de uma ordem justa e pretendente à universalidade, e engloba os fundamentos dos argumentos que as pessoas geralmente desenvolvem para justificar suas posições nos conflitos (Dodier, 1993, p. 80).

As pessoas são capazes de escolher o tipo de cidade sobre a qual desejam apoiar-se. Alcança-se a paz e a justiça quando todos os seres pertencem ao mesmo mundo (porém, admite-se que há ações por amor que não são justificadas). $\mathrm{O}$ modelo propõe uma avaliação das competências de julgar e se engajar em diferentes mundos - o que não se dá sem dor -, captadas, via de regra, em sequências curtas. Segundo Dodier (1993), para Levi-Strauss, o agente tem disposições duradouras no plano inconsciente, as quais convivem com o nível dos motivos aparentes, nesse caso, também duráveis. Goffman também vê os atores agindo de forma estratégica, com interesse pessoal disfarçado, casos em que os motivos aparentes não são os reais, de modo que o horizonte imediato é carente de dignidade teórica, importando só o desvelamento.

Boltanski e Thévenot não projetam as justificativas das pessoas para um plano de motivos ocultos. A ideia não é situar os agentes dentro de um sistema de relações, mas identificar os recursos mobilizados pelos agentes para julgar e agir, isto é, avaliando de que mundo falam. O sociólogo é liberado para manter-se atento à sucessão de situações em que ocorrem julgamentos e interpretações dos agentes. A possibilidade de oscilar entre um regime de ação a outro dá conta da incerteza com a qual são confrontadas as pessoas, avaliando-se o custo da passagem de um regime a outro. Dessa forma, as entrevistas devem indagar sobre as razões das ações dos atores, mas não para acessar seus motivos internos.

A sociologia da crítica recusa-se a crer (como creem as perspectivas oriundas de Weber e Durkheim) que podemos explicar os motivos dos atores de forma muito diferente do que eles mesmos já dizem. Do outro lado, está a teoria pluralista, isto é, o sociólogo fala de um mundo e contempla a fala dos outros. Nesse sentido, o desvelamento, que é, por sinal, um ato de denúncia, nos coloca em um dos mundos, embora não o digamos, à medida que denunciamos outro.

O enfoque dos mundos nos permite compreender a fala do MST (e da assistência técnica engajada) numa cidade cívica, ${ }^{2}$ mesmo em sua con-

${ }^{2}$ Nessa perspectiva, os atores sociais (ocidentais) se valem do princípio de justificação mais ou menos universalizado e incorporado. Um deles foi chamado de cidade cívica, onde os atores agem e se baseiam no princípio de que os laços entre as pessoas são mediatizados pela vontade coletiva (Dodier, 1993). É o caso das assembleias, dos núcleos do MST, etc. 
figuração socialista, ${ }^{3}$ em que os laços entre as pessoas são mediatizados pela vontade coletiva. Essa cidade parece se chocar com a "cidade doméstica" em que vive grande parte dos assentados, representando os valores camponeses, no qual a reciprocidade é o elemento fundamental. Muitas vezes, ao serem questionados sobre o porquê da evasão de tantos assentados, os depoimentos vieram no sentido de "acusar" o evadido de não ser agricultor (embora, praticamente, todos sejam originários de pequenos municípios agrícolas do Estado), reafirmando, com isso, muito mais a identidade camponesa (ou a "cidade doméstica”) daquele que fica na terra.

Esses fatos nos permitem observar, portanto, como os discursos se valem de diferentes cidades para possibilitar os acordos possíveis que são construídos pelo trânsito entre os mundos, a exemplo da tentativa dos assentados de construírem a paz via o rito de passagem pelo acampamento por parte dos parentes que querem obter lote, pela aceitação dos grupos de crédito e dos projetos técnicos, ou mesmo pela escolha do representante do MST nos assentamentos. Essa abordagem nos instrumenta, também, na compreensão da pentecostalização dos assentados e seu concomitante afastamento do MST. Está sendo gestada uma "nova cidade"? Ou essa aproximação é um caminho eficiente para a recomposição da "cidade doméstica”? Ou, ainda: a evasão (ou a ida para a cidade) nos indicaria a crescente importância de "novas cidades" no panorama simbólico dos assentados?

Em suma, na análise proposta, mesmo levando em consideração que, como afirmamos anteriormente com relação à (falsa) dicotomia entre arcaico e moderno, não devemos substancializar as "cidades" propostas pela sociologia da crítica, nem adotá-las literalmente, e sim, como idéia geral, relacionandoas ao que chamamos de "projetos" (camponês, socialista, empresarial, rentista). Isso implica admitir algumas analogias, como a do projeto camponês coma "cidade doméstica", uma vez que comungam princí-

${ }^{3} \mathrm{O}$ projeto socialista do MST foi estudado por diversos autores. Para uma revisão, ver Silveira (2003). pios de justiça que mantêm proximidade.

Passemos à análise dos casos, na tentativa de aplicar as perspectivas propostas.

\section{OS ASSENTAMENTOS}

Tanto o assentamento Apolo (34 lotes) quanto o Santo Ângelo (17 lotes) foram implantados, em 1996, pelo INCRA, com beneficiários vindos de grupos do acampamento de Cruz Alta, do norte do Estado. Esses, no caso do Apolo, representavam quase que perfeitamente as famílias e as religiões. Todos receberam rapidamente uma pequena soma de dinheiro, em torno de mil reais, para a alimentação básica e utensílios. Em 1997, acessaram o antigo "crédito habitação", que, na época, correspondia a dois mil reais, soma muito pequena para levantar uma casa, apenas lhes possibilitando construir galpões. Todos os assentados, entre 1996 e 1998, tiveram acesso ao crédito através do Programa de Crédito Especial para Reforma Agrária (PROCERA), ${ }^{4}$ distribuído para todos sempre em épocas muito semelhantes (após os conflitos, as famílias consideradas irregulares pelo INCRA passaram a não acessar mais recursos). A luz chegou em 1998, e a captação de água apresenta deficiências até esta data. Como agravante, somente em 2005 chegou a linha de coleta de leite.

Dividindo a história do assentamento Apolo em quatro fases, ainda em 1997, uma família extensa, com cinco famílias nucleares, recém convertidas a evangélicas, saiu do assentamento, por meio de troca de lotes. Segundo o mais velho, eles saíram, em princípio, porque não queriam ficar em várzeas, embora se afirmasse que "a coisa aqui não vai dá boa”, numa previsão de conflitos no assentamento. As dificuldades de solo, clima, estradas, crédito e assistência técnica levaram quase todos os agricultores, especialmente os que ganharam lotes de várzea (mais difíceis de trabalhar), a arrendar as terras. Começaram cedo, portanto, as

\footnotetext{
${ }^{4}$ Esse Programa, em 1999, foi substituído pelo Programa Nacional de Fortalecimento da Agricultura Familiar (PRONAF).
} 
investidas dos fazendeiros nesse assentamento e as disputas pelo controle do espaço de mediação, tanto com relação à coordenação do assentamento, quanto pelos recursos naturais, principalmente a água de irrigação do arroz e a própria terra, que, juntos, representavam o controle do arrendamento, como demonstra a fala a seguir. A disputa se deu entre grupos que cometiam crimes juntos e se desentendiam frequentemente, inclusive com relação a infidelidades conjugais, gerando rivalidade e redundando em sucessivas mortes por vingança a partir de 1998.

OD. era coordenador de um grupo, o V., do outro [...] vieram com umas certas divergências desde o acampamento [...] também por disputas de liderança dentro do assentamento [...], um grupo queria dominar o restante e o outro de certas partes não aceitava aquela proposta [se referindo ao controle do arrendamento, inclusive e cita:], nós que achemos os cara que arrendam pelo valor tal e é esse, e vocês tem que obedecer ... (Liderança do MST).

Nessa primeira fase, ocorreu a saída de sete famílias beneficiárias, sendo uma por morte, cinco famílias evangélicas, e uma assentada que trocou de lote após sua separação com um dos envolvidos no conflito. Uma segunda fase se inicia após a festa de dois anos do assentamento, em 21 de novembro de 1998, quando alguns envolvidos no conflito anterior doaram uma vaca para o churrasco, demonstrando sua liderança. Na oportunidade, um deles foi assassinado e dois baleados, o que acarretou a saída de três assentados: os dois atiradores e o irmão de um deles, que conseguiu, posteriormente, trocar de lote, indo para o norte do Estado.

O conflito foi o estopim para a mudança de rumos no assentamento. No dia seguinte, surgiu um abaixo-assinado com mais de 70 assinaturas, que pedia providências do INCRA. Várias famílias, tanto aquelas que se diziam ameaçadas quanto os pretensos ameaçadores, pediram para sair (trocar de assentamento), fato registrado no Processo de Sindicância (INCRA, 2001). Em 1999, saíram outras tantas famílias e, também, o coordenador do assentamento, alegando perigo de vida e dificuldades em lidar com as várzeas. Uma delas con- seguiu trocar de assentamento, mas as outras simplesmente o abandonaram, pois não era fácil obter lotes no norte do Estado. Diversos relatos demonstram que o INCRA, nesse ínterim, não tomou providências imediatas, propondo antes uma sindicância. O depoimento de um técnico da COPTEC revela a hesitação do INCRA e do MST quanto à troca de lote:

O próprio pessoal que estava envolvido propôs de trocar; aí, como não era liberado a questão da troca, não foram autorizado tanto pelo INCRA, e o pessoal do Movimento como era uma coisa que o próprio INCRA dizia que não pode trocar, o movimento também aderiu àquela estória das trocas [...], na verdade na época, pelo menos se julgava que não era permitido, até porque se liberar troca dentro do assentamento, agora mesmo tem uns problemas de troca que o pessoal voltou atrás... (Técnico da COPTEC).

Para além dos conflitos em si, observa-se uma tentativa constante de voltar às regióes de origem dos assentados (norte), onde as trocas de lote (tanto internas como externas) tinham uma motivação bastante relacionada ao parentesco e aos grupos de reciprocidade (inclusive religiosos). O que se constata é uma luta dos assentados contra orientações do INCRA e o mandonismo do MST para viabilizar seu projeto corporativo, mesmo quando já se delineava, ali, a presença de projetos rentistas e empresariais.

Na sequência, até o ano 2000, mais três pessoas envolvidas no conflito foram assassinadas, inclusive no norte do Estado. Essa situação de conflitos e ameaças provocou uma ampliação da rotatividade no assentamento, expressa por mortes, desistências (por medo, por exemplo) e, principalmente, nas trocas para outros assentamentos. Além das saídas, com a vacância dos lotes, ocorreu um rearranjo interno no assentamento na ocupação desses lotes. Muitas famílias acabaram trocando de lote para fugir das áreas de várzea, ou para se aproximar de outros membros de suas famílias.

Mesmo que a sequência de conflitos e de crimes tenha se dado por um pequeno grupo de assentados, e $\mathrm{o}$ arrendamento das terras abarcasse a quase totalidade deles, a sindicância (criada para lidar com o alto índice de conflito no assentamen- 
to) acabou se detendo mais nos problemas do arrendamento de gado e de arroz. Movido pela suposição de que o fenômeno do arrendamento estava relacionado com os crimes, o INCRA, junto com a Polícia Federal, fez uma devassa no assentamento. Numa operação sui generis, vistoriou-se cada lote, procurando encontrar aqueles denominados "preguiçosos" e verificar o "mau uso dos recursos públicos” (INCRA, 2001), concluindo-se pela expulsão de uma parte significativa dos assentados. $\mathrm{O}$ arrendamento, contudo, em todos os assentamentos da Região, parece ser motivado pelas frequentes frustrações de safra, falta de assistência técnica, tida por boa parte dos assentados (até hoje, inclusive) como péssima ou inexistente, e falta de infra-estrutura, como água, luz e estrada.

As ações da sindicância acabaram reproduzindo uma situação semelhante ao relatado por Elias e Scotson (2000), em que alguns poucos "maus elementos" legitimam o estigma. Embora a disputa por recursos naturais - entre eles, a terra e a água - tenha provocado situações de violência, boa parte dos assentados do Apolo não se envolveu diretamente nas disputas, mas nem por isso deixaram de arrendar seus lotes, por força das contingências. Convencida pelos agentes do INCRA, a Polícia concluiu o relatório sugerindo mais do mesmo com relação à nova ocupação dos lotes, ou seja, acatar as indicações do MST (promover a seleção de famílias dos acampamentos), já que os “problemas” teriam ocorrido devido à má seleção das famílias. Mais uma vez, recorre-se a explicações essencialistas, lugar comum nos órgãos de terra, atribuindo o "fracasso" da reforma agrária às suas vítimas.

Após a sindicância, o Superintendente do INCRA acompanhou a reformulação do assentamento e acabou não implementando uma parte das medidas colocadas pela equipe, apenas advertindo os arrendadores, mas sem expulsá-los. Porém, nesse momento, diante dos dezoito lotes vagos, correspondentes às famílias que saíram, o INCRA, alegando que se tratava de uma emergência, optou por realizar uma intervenção e trouxe dezoito novas famílias, sem prévia discussão com o grupo local, embora fossem exigência as atas de aprovação. ${ }^{5}$ Algumas dessas famílias foram "selecionadas" para o trabalho com arroz, pois eram arrozeiros, solução que levou em consideração apenas o aspecto técnico-produtivo, deixando de lado os outros aspectos. Os relatos revelaram o descontentamento dos assentados com relação às suas poucas possibilidades de intervenção política no assentamento, frente à predominância do INCRA e do MST. Isso significa que, para os assentados - especialmente os não-alinhados - há pouca margem de manobra, a exemplo da escolha dos novos assentados, deixando visível a tendência, dos técnicos e do MST, em estabelecerem relações de tutela, quando eles “não se organizam”, como já havia apontado Martins (2003).

As reacomodações internas e a entrada de novos assentados encerraram a segunda e mais tumultuada fase, período de maior rotatividade e evasão de assentados, quando ocorreu a saída de vinte e duas pessoas, por falecimentos, trocas e a saída daqueles que não chegaram a se regularizar, embora tenham ocupado o assentamento por algum tempo. Alguns eram proprietários, moradores ou até pequenos empresários do município, que se aproximaram de algumas famílias do assentamento para arrendar ou obter lotes de terra. Essa intrusão revelou o quanto o MST tinha pouca representatividade nesse assentamento, mas não na sua relação com o INCRA, uma vez que alguns pretendentes tiveram processos abertos, mas não foram aceitos ali.

Observamos que algumas mortes, além da motivação relacionada ao puro cálculo para acumulação (roubo, por exemplo), também contaram com elementos referentes à reciprocidade negativa, na forma de vendettas. Mesmo quando não estava mais em jogo a disputa por terra no assentamento, quando os envolvidos nem mais moravam no município, seguiram ocorrendo mortes de am-

\footnotetext{
${ }^{5}$ É prática corriqueira a exigência de aprovação de novos assentados pelo conjunto dos residentes do assentamento, por meio de ata. Elas são muitas vezes forjadas ou construídas mediante ameaça. Para evitar isso, atualmente o INCRA propõe só aceitar atas feitas na presença de supervisores de projeto, o que nem sempre ocorre.
} 
bos os lados, demonstrando que, possivelmente, estavam em jogo valores morais, tais como a honra, e que havia, no assentamento, ao menos um embrião de uma comunidade de reciprocidade.

No final de 2001, inaugurou-se uma terceira fase no assentamento. Com a entrada intempestiva de novas famílias, desenvolveu-se uma rixa inicial entre os "velhos" e os "novos", reeditando as disputas de poder pelo controle da terra e do arrendamento, dessa vez, porém, de forma mais branda. Há relatos de assentados do grupo dos "novos" afirmando que, quando chegaram, seus lotes não tinham cerca e estavam ocupados pelos animais dos “antigos", gerando desentendimentos:

Chegou dezesseis do acampamento, deu aquela meia confusão assim entre os assentados mais velhos e os mais novos, em função de um querer mandar mais que o outro, eles queriam meio que botar ordem [...] eles não queriam nem que fizesse cerca...” (Assentado novo).

Mas, mesmo enfrentando tais dificuldades, os assentados desenvolveram mecanismos de construção de alianças. A crescente presença de moradores da região ampliou a teia de relações sociais do assentamento de forma paralela ao reagrupamento familiar (embora esse fenômeno tenha se dado de forma menos intensa que no assentamento Santo Ângelo, devido às circunstâncias mais adversas, que permitiram uma menor margem de manobra para os assentados). Nessa fase, continuaram ocorrendo os arrendamentos nas várzeas, mas também os cultivos próprios dos assentados, pois alguns assentados novos tinham experiência prévia e capital para a produção do arroz. Em 2002 e 2003, na esteira do arrefecimento dos conflitos, não ocorreram saídas no assentamento.

Paralelamente à "intervenção branca" relatada anteriormente, ainda em 2001, o INCRA incluiu o assentamento no então incipiente PAC, ${ }^{6} \mathrm{O}$ qual iniciou a sua efetivação somente em 2004. Inaugura-se, aqui, uma quarta fase, que promoveu

${ }^{6}$ Programa-piloto de Consolidação e Emancipação (Autosuficiência) de Assentamentos Resultantes da Reforma Agrária, que contava com recursos consideráveis. um novo rearranjo de forças dentro do assentamento, na medida em que apresenta duas peculiaridades importantes: dispõe-se de uma considerável soma de recursos para investimentos e para a contratação de uma assistência técnica mais equipada, mais do que normalmente o INCRA investe. E também, por definição metodológica, o PAC exige que os assentados formem uma associação, para que eles mesmos gerenciem os recursos alocados. Ou seja, a nova proposta metodológica apresenta potencial de promover rearranjos de poder.

A associação formada está se configurando como a grande instância de poder dentro do assentamento, provocando uma disputa por esse novo e rentável espaço de mediação. Essa disputa conta com a participação das duas principais forças que agem dentro do assentamento: o MST, que, embora cada vez mais enfraquecido, ainda controla a assistência técnica, chave para obtenção de recursos, e a Assembléia de Deus, pois o encarregado da Igreja na localidade foi eleito presidente da Associação, mesmo que os evangélicos sejam minoria, quando comparados com os católicos. No momento da entrevista, essa liderança estava construindo uma igreja no assentamento vizinho, Recanto, demonstrando o crescimento de sua religião na localidade.

É muita promessa e nada feito, é uma tormenta num copo d'água, isso é uma coisa que ninguém mais... o pessoal tá desiludido, ninguém mais, é isso aí, e quando vem dinheiro, daí eles querem dinheiro, é isso e aquilo, é desconta aqui, desconta ali, quando vê virou em nada, e nós temo sempre endividado, sempre atolado, atolado, daí a coisa não é fácil [...] quando vem o dinheirinho a gente sempre tá contribuindo e não é contribuindo, é assim uma coisa que é quase forçado, porque se o cara diz que não contribui, corta isso, corta aquilo... (outra liderança evangélica assentada).

Porque que a pessoa toma cachaça, não é porque tá bem, a pessoa toma cachaça para se esquecer. A cachaça é uma coisa que vai prá cabeça, deixa a pessoa alegrinha, deixa a pessoa meio burrinha, entendeu? A cachaça não tira a luta, não arranca o problema de ninguém [...] se o homem não está na cachaça, ele não briga fácil [...] A Assembléia de Deus, aqui e em qualquer assentamento do Estado e do País, ela é respeitada pelo MST, tanto a Assembléia de Deus respeita o MST, porque o MST é uma organização, e sendo uma organização, deve ser respeitado (Pastor evangélico da cidade).

A fala do pastor demonstra que, nesses as- 
sentamentos (ele atua em todos), parece estar havendo uma tentativa de regeneração ou de criação de uma situação nômica, em que a Assembléia de Deus, perante a fragilização dos assentados, em ambientes novos e conflituosos, surge com a proposição de novas possibilidades de organização social, através de cultos frequentes, do controle do alcoolismo e, consequentemente, da violência. É visível a ascensão dos pentecostais, que vão, aos poucos, conquistando até os católicos, processo quase concomitante a um razoável afastamento do MST, pois, apesar do discurso evangélico se distanciar de qualquer forma de confronto e procurar manter uma boa relação com todas as forças atuantes no assentamento, a primeira fala do assentado evangélico acima não esconde o que, realmente, está em jogo.

A ascensão dos evangélicos, apesar de serem chamados de "cabeça fraca” pelos católicos, fica patente também em sua participação nos grupos de crédito, hoje, em número de quatro no assentamento: dois de famílias antigas (PROCERA), coordenados por dois evangélicos; e dois de famílias novas (PRONAF A), coordenados por católicos e evangélicos. Esses grupos foram formados por proximidade, e não necessariamente por afinidade, o que não contribuiu para amainar os conflitos, na medida em que, muitas vezes, não há cumplicidade e confiança, ou seja, valores humanos que o viabilizem. ${ }^{7}$

Em suma, os assentados passaram a viver uma situação de crescente agregação, com ênfase na evangelização das famílias, após um razoável período de medo e violência, com alguns grupos armados praticamente controlando o assentamento. Após a saída de boa parte dos grupos rivais, reiniciou-se (ou iniciou-se tardiamente) a (re) corporação familiar e as negociações com os vizinhos na ocupação dos lotes, caracterizando um

${ }^{7}$ Um exemplo disso é o aval solidário para o crédito rural, que tem sido, claramente, uma imposição, não espelhando relações de reciprocidade. Com isso, parece facilitar o atrito entre as famílias quando uma não paga a conta, ou quando há uma saída do assentamento, recaindo a dívida sobre os outros integrantes do grupo, fato que ocorreu durante a vigência do PROCERA e do PRONAF A, sendo, hoje, uma questão preocupante nos assentamentos gaúchos. processo de ampliação da rede de relações sociais, embora ainda ocorram situações violentas, como roubos e ameaças. Nesse período, até a data da entrevista (inverno de 2005), houve três saídas e a ocorrência de um assentado em vias de sair. Somando as saídas das quatro fases, computamos trinta e três saídas para trinta e quatro lotes, sendo que quatorze representaram evasões.

O assentamento Santo Ângelo, logo na origem, teve um dos seus dezessete lotes condenado por alagamento, e o seu ocupante transferido para outro assentamento. $\mathrm{O}$ assentamento é considerado de má localização, e vários lotes ainda ficam sem acesso quando ocorre muita chuva. À semelhança do Apolo, as dificuldades ambientais (solos arenosos e pluviosidade baixa), além dos problemas de infraestrutura, assistência técnica e crédito, levaram uma parte dos assentados a arrendarem suas terras, fato que, para alguns assentados (aparentemente, poucos), ocorre até hoje.

Foi formado, ainda no acampamento, um grupo de dez pessoas para trabalhar de forma coletiva, mas dois irmãos e um amigo foram os primeiros a abandonar o grupo, ainda em 1998, por estarem, em princípio, localizados em lotes com dificuldades de acesso. Todavia há relatos que dão conta de desentendimentos com relação ao modelo tecnológico a adotar pelo grupo, pois os irmãos queriam trabalhar somente com a agroecologia (eles estudaram na escola agrícola ligada ao MST) e o resto do grupo preferiu não arriscar, iniciando somente a implantação de uma horta ecológica. O coletivo esfacelou-se em 1998, devido aos problemas de infra-estrutura, de desvio de recursos para a construção de casas e por desentendimentos internos (desconfiava-se de uma das lideranças). Ocorreram, ainda, duas separações de casais, o que parece ter motivado a saída de um dos homens. Uma assentada traduziu o sentimento daqueles que não eram do coletivo, reclamando de uma tentativa de se apossar da sede do assentamento e das áreas secas, de maior valor de uso, embora tenha vencido a tese do sorteio dos lotes: 
Eles queriam ser mais que nós, eles, muitas vezes, eles se exaltavam, dizendo que iam ter mais que nós, porque nós não quisemos entrar no grupo deles, né? Diziam que era aquela coisa, coisa de preto, que nem o meu marido e o irmão são morenos, né? Era coisa de preto de não entrar em grupo, entendeu? Então nós comprava alface deles, nós que comprava, porque eles produziam nós comprava [...] eles queriam ficar de dono da sede, o plano deles era ficar eles aqui em cima, de dono da sede, trabalhar agrovila e nós ir morar lá prá baixo nos banhado, porque nós era individual... (Assentada no Santo Ângelo).

Aspectos relacionados à etnia e ao modo de produção e de organização tomaram parte no discurso da assentada, na busca de demonstrar a tentativa de dominação por parte do "grupo coletivo" sobre os "individuais", o que parece ter causado uma cisão interna, pelo menos no princípio do assentamento. A assentada lançou mão de um "mundo da tradição", em contraposição ao "mundo cívico" proposto, embora tenha demonstrado trânsito nesse mundo e que ainda se movimenta como uma "liderança" (trata-se da pessoa que mais interveio na reunião inicial com todos os assentados). Alguns integrantes relataram que trabalhavam mais que outros, de modo que se sentiam injustiçados no coletivo, demonstrando o desconforto que representava o controle do tempo de trabalho de cada um por parte do grupo, num evidente choque de "mundos".

Observa-se, aqui, uma união mal sucedida de pessoas motivadas pela propaganda ideológica do coletivismo, comprimidas pelas argumentações de sua superioridade técnica e humana, típicas de processos de violência simbólica. ${ }^{8}$ Dos dez participantes do "coletivo", saíram seis, sendo, duas trocas e quatro evasões. O outro grupo, de "individuais”, tinha sete pessoas, das quais saíram quatro, sendo apenas uma evasão, somando cinco evasões e rotatividade de dez no assentamento.

Valoriza-se a entrada de parentes no assentamento, os quais estão, aos poucos, ocupando os lotes vagos, mediante um acordo entre os grupos, sem uma aparente concorrência aberta. O assenta-

${ }^{8}$ Violência que extorque submissões que sequer são percebidas como tal, apoiando-se em crenças socialmente inculcadas. Em outras palavras, é aquela que é legitimada pelo violentado, como que sujeito e objeto ao mesmo tempo (Bourdieu, 1996). mento está desenvolvendo um processo de crescente corporação, ainda que de forma negociada com o MST. Pois a exigência de incorporar os já acampados, feita pelo MST e pelo INCRA, foi aceita e todos encamparam. Dos oito que entraram, quatro eram parentes de algum assentado e quatro oriundos da vizinhança. Um deles acionou parentes em assentamento próximo. ${ }^{9}$ O lote condenado ainda é objeto da cobiça, isto é, está em curso mais uma etapa corporativa. Chegarão a um novo acordo?

As relações com os fazendeiros se configuram, principalmente, pela comercialização de produtos e pela contratação de serviços temporários, as quais são mais bem aproveitadas por aqueles assentados oriundos da localidade, cada vez mais presentes nos lotes. Conforme um assentado, apesar de ter melhorado com o tempo, essa aparente boa relação pode ter sido maculada pelas desconfianças de abigeato que pairam nas proximidades do assentamento. Foi o caso de um ocupante não regularizado que, por meio de troca (e sem consulta aos outros) residiu por dois anos no assentamento, aparentemente cometendo crimes, conforme vários relatos:

[falando do ocupante] nós tivemos que ser obrigado a tirar, ele não respeitava a família dele, bebia, incomodava [...] ninguém se importava [...] a menina ele queria atacar pro lado dela, no caso [...] foi duas ou três, eu denunciei ele prá polícia, fiquei aqui e denunciei, e as crianças eu liguei pro Conselho Tutelar e a mulher veio aqui em casa e eu contei a verdade e disse prá ela, e a senhora pode dizer que fui eu e eu assumo, já que não tem um homem prá fazer isso aí, eu faço, eu me responsabilizo. E eles retiraram as crianças daí, aonde a polícia veio, daí que descobriram que ele até já tinha matado um cara... (Assentada no Santo Ângelo).

[...] Ele matou uma ovelha do vizinho a tiro, então foi como ele teve que sair, porque nós não aceitamos [...] já estava sendo anunciado na rádio que tinha gente fazendo este tipo de coisa [...] era só ele... (Assentado no Santo Ângelo, grifo nosso).

Apesar da gravidade de alguns atos, muitos relatos sobre ele são vagos, com afirmativas do tipo "ele nunca me incomodou”. O fato é que a comunidade parece ter vacilado para viabilizar a sua

${ }^{9}$ Há relações políticas, de parentesco e religiosas entre os assentamentos do Estado, deixando claro que estamos em frente de uma teia maior de relações sociais. 
expulsão. Um técnico do INCRA apresentou esse caso como um indicativo da falta de união nesse assentamento, ou seja, a existência de relações sociais fracas e pouco regradas, na comparação com comunidades camponesas tradicionais. Trata-se de uma "comunidade" que aceitou (ou não conseguiu evitar), de alguma forma, conviver com alguém “de fora” e com um comportamento discutível. Por outro lado, o episódio do roubo da ovelha, noticiado na rádio local, demonstrou que o assentamento não estava disposto a ver a sua imagem arranhada perante a sociedade maior. Observa-se, no relato acima, um discurso moralizante, ressaltando os valores camponeses e apressando-se em enfatizar que a coletividade não comungava com a atitude criminosa. Ainda que tardiamente, funcionou um mecanismo de expurgo, como relata a assentada na fala acima (a mesma que denunciou o grupo coletivo), ainda que fazendo o contraponto com certa autolouvação, relativa a outros assentados, com relação à boa convivência de todos, pois insinua que a resolução do caso se deveu à sua intervenção. Para um técnico do MST, essa assentada é uma liderança que hoje está na “oposição”, evocando a perspectiva cívica do MST para afastá-la do mundo da tradição camponesa e desmascará-la.

Atualmente, existem dois grupos principais de relação no assentamento - católicos e evangélicos. Vários entrevistados fazem referência a isso, embora também digam que não há divisão no assentamento e que todos são unidos, num discurso vago, mas que demonstra que, se não há a união desejada, pelo menos ela é bastante buscada, como se esperaria de uma pequena comunidade camponesa. Há pontos importantes de união na rede de relações sociais do assentamento, aproximando os grupos via amizade, religião ou parentesco e possibilitando uma lenta, mas crescente consolidação de laços sociais.

Entretanto, na vacância de um lote, as relações religiosas e de reciprocidade, relacionadas com parentesco e amizade podem provocar dissonâncias com as definições do MST, especialmente com relação à obrigatoriedade do prévio acampamento, ou mesmo gerar relações clientelísticas com os media- dores. Aqui se materializam os diferentes projetos, afirmam-se as identidades, estabelecem-se negociações mais duras entre os "mundos”, abrindo a possibilidade da corporação ou da desagregação, como vemos nas falas a seguir:

[se referindo aos evangélicos:] pelo método que eles usam de convencer as pessoas, eles tem mais jeito que os católicos. [Sobre a ocupação de lotes vagos:] Os evangélicos chamavam eles que já eram evangélicos, eles conheciam, depois foi aumentando [...] o movimento tem um certo acordo, de troca de lote e tudo, se é para unir famílias, a gente concorda. [mas lembra que] tem uma regra [do MST] que a pessoa tem que estar no mínimo seis meses acampadas, que no acampamento tem uma certa formação que tu dá para essas famílias, para ele ter uma noção do que é assentamento, ter um lote de terra, produzir [...] conhecer a parte organizativa do assentamento [...] porque se tu pegar uma pessoa que nunca foi acampada [...] é pra criar problema (Liderança do MST).

Se tiver vaga, tiver um lote aí que desse para colocar ele [filho], eu gostaria, porque ele é novo, tá com todo o tempo prá trabalhar, né? [mas acharia melhor se não precisasse acampar] (Assentado no Santo Ângelo).

Percebe-se, na liderança do MST (católico), uma apreensão perante a ascensão dos evangélicos e a sua influência na ocupação dos lotes vagos. Realiza uma transição para o mundo doméstico, percebendo a importância, ainda que de forma ambivalente, do parentesco e da capacidade de os evangélicos lidarem com os camponeses. Mas, ao ser perguntado diretamente sobre a questão, retoma o projeto cívico-socialista e demarca a posição do MST, a necessidade do acampamento e de conhecer a "organização" do assentamento (ou seja, a hierarquia proposta pelo MST mesmo). Por outro lado, a fala do assentado revela o desejo da recorporação familiar (o que Martins chamou de "reforma agrária dentro da reforma agrária”) e a difícil negociação com o MST, que não abre mão do acampamento.

\section{EVASÃO E ROTATIVIDADE}

A evasão no Santo Ângelo atinge a média dos assentamentos criados entre 1996 e 1998, em torno de 30\%. Não constatamos nenhuma correla- 
ção da evasão com dados secundários sobre infraestrutura, porém tais evasões ocorreram, todas, em lotes que sofrem algum grau de alagamento, corroborando a justificativa que todos os assentados levantaram e demonstrando uma especificidade não captada através dos dados secundários, pois há trechos que alagam e impedem a passagem do caminhão do leite e do transporte escolar. Contudo, algumas saídas ocorreram quando a estrada já estava melhor, e relatos demonstraram que, mesmo em alguns casos, em que o discurso dos agentes apresenta uma motivação material, seja ela por um melhor solo ou por uma melhor infraestrutura, constatamos outras motivações, por vezes implícitas - como a recorporação familiar ${ }^{10}$ ou a exclusão de uma comunidade-, que influem nas decisões dos agentes.

A maior evasão (41\%) e rotatividade (97\%), no Apolo, são explicadas pela maior intensidade dos conflitos. Além de disputas por mulheres, os conflitos entre grupos corporados (inicialmente ligados a crimes, a parentesco e, depois, à religião) ocorreram pela hegemonia das terras e da água e, consequentemente, da relação com os arrendatários, indicando uma maior preponderância do projeto empresarial e rentista, ainda que negociado com camponeses engajados na ampliação de suas fronteiras de poder. A dificuldade de estabelecimento do projeto camponês e o próprio não estabelecimento do projeto socialista, por conta dos conflitos, demonstram que o Apolo está numa fase menos avançada da corporação camponesa.

Para os dois assentamentos, constatamos uma grande diferença na evasão entre solteiros ${ }^{11}$ $(38,9 \%)$ e casados $(16,4 \%)$. As diferenças em rotatividade são menores, com $66,7 \%$ e $42,5 \%$, respectivamente, o que indica, ainda assim, uma clara tendência de maior mobilidade entre os solteiros. No Santo Ângelo, a evasão entre evangélicos foi maior $(28,6 \%)$ que entre católicos $(8,3 \%)$; porém, a rotatividade foi ligeiramente menor entre

${ }^{10}$ Conforme o conceito de comunidade corporada de Wolf (2003).

${ }^{11}$ Comparamos sempre dentro de cada grupo, ou seja, o percentual de solteiros que evadiu com relação aos solteiros somente, e assim, sucessivamente. os evangélicos (35,7\%) do entre católicos (41,7\%). No Apolo, embora ocorra um bom número de evangélicos (17 famílias) em relação aos católicos (48 famílias), a evasão entre os evangélicos é zero, só ocorrendo entre os católicos. A rotatividade entre os católicos $(58,3 \%)$ é quase o dobro daquela verificada entre os evangélicos, com 29,4\% (Mello, 2006).

Essas constatações são explicadas a seguir, nas conclusões deste trabalho, quando procuramos articular as perspectivas teóricas adotadas com alguns fenômenos sociais observados nos assentamentos.

\section{CONCLUSÕES}

A rotatividade é mais alta, num primeiro momento, e depois diminui de ritmo, nos trazendo pistas sobre a temporalidade de um processo maior de construção da coesão social, especialmente pela via do parentesco e da religião. Agentes com menor vínculo social, como aqueles não relacionados por parentesco e religião, solteiros e separados, têm maior mobilidade. As trocas para outros assentamentos, mesmo de casados, têm uma motivação especial de reencontro familiar, podendo ser facilitadas pela rede de relações religiosas que se estabelece entre os assentamentos. E ainda: as exclusões resultantes da conformação dessas redes podem gerar saídas, às vezes com o uso de violência física.

Assumindo a construção da coesão social ou de uma rede de relações de reciprocidade como fator preponderante para a permanência no assentamento, pelo menos como uma tendência, é razoável supor que o casamento permite o alargamento dessa rede e, conseqüentemente, uma maior estabilização. Os agentes em busca de parceiros tendem a tornar o ambiente mais "conturbado", mesmo considerando o ocorrido no assentamento Apolo, onde as disputas por mulheres, entre casados, foram um elemento complicador das rivalidades entre os grupos.

Com relação à religião, ocorrem processos 
diferentes nos dois assentamentos. Enquanto, no Apolo, não houve evasão de evangélicos; no Santo Ângelo, ela foi preponderante, o que indica que o processo de normatização moral e de construção das relações de reciprocidade entre os evangélicos, mesmo sendo, nos casos estudados, mais intenso que entre os católicos (os relatos, inclusive dos católicos, confirmam isso), não pode ser entendido de forma determinística, pois as configurações locais precisam ser avaliadas. A tendência de menor rotatividade entre os evangélicos corrobora a idéia de que a pentecostalização, nos dois assentamentos estudados, tem se mostrado um fator importante de coesão social, através do envolvimento dos praticantes em atividades coletivas e, fundamentalmente, porque dá conta de conter conflitos, através do controle do alcoolismo e das drogas. A “organização” desse grupo também possibilita assumir espaços de poder dentro do assentamento e na relação com "os de fora”, a exemplo do INCRA.

Esse processo de corporação é reconhecido e estimulado diferentemente pelos agentes do MST, pelos técnicos e pelos assentados, num campo de lutas que também envolvem projetos não corporativos e até urbanizantes. Por sua vez, os impactos dos conflitos entre esses projetos se dão num ambiente permeado marcadamente pelas contradições resultantes da dominação econômica e simbólica do mundo dito moderno. Constatamos as famílias alcançarem a paz e para conter a evasão, mesmo que isso implique, num primeiro momento, a gradativa saída dos que não têm vínculos sociais maiores.

Desconfiando da suficiência do desvelamento para a compreensão dos fenômenos sociais, como a rotatividade e a evasão, procuramos nos valer das contribuições propostas pela sociologia da crítica e nos dar conta das diferentes "cidades", suas implicações nas ações humanas, e, também, da nossa cidade, evitando o perigo que tal desconsideração enseja. Não se trata, todavia, de uma filiação irrestrita a nenhuma escola de pensamento, e sim, de uma tentativa de nos valer de aspectos de várias teorias para demonstrar que a tendência à ampliação da coesão social em assentamentos é bastante relacionada ao desenvolvimento de uma identidade "nós", por meio do reavivamento da sociabilidade camponesa. Ela se dá, fundamentalmente, numa dimensão doméstica, em que o exercício da reciprocidade, princípio estimulador do desenvolvimento de valores humanos, viabiliza o laço social e a própria idéia de comunidade, calcada, principalmente, no parentesco, na religiosidade e no alargamento da rede de relações com os vizinhos.

Percebe-se que, não sem ambiguidade, os assentados estão lentamente trilhando esse caminho, embora de forma negociada com outros agentes, muitas vezes engajados em outros projetos ou "mundos", tais como o projeto socialista, do MST, e da assistência técnica, o projeto empresarial (representado pelas relações de dominação de fazendeiros vizinhos, ou mesmo de assentados diferenciados) e ao próprio rentismo de alguns assentados, como percebeu Martins (2003), por vezes, mediante relações assimétricas de reciprocidade.

(Recebido para publicação em setembro de 2007) (Aceito em abril de 2008)

\section{REFERÊNCIAS}

BOLTANSKI, L. L' amour et la justice comme competences. Paris: Métailié, 1990.

BOURDIEU, P. Razões práticas: sobre a teoria da ação. Campinas: Ed. Papirus, 1996. 
. Reprodução proibida: a dimensão simbólica da dominação econômica. In: O campo econômico: a dimensão simbólica da dominação. São Paulo: Ed. Papirus, 2000. p.93-119.

CAILLÉ, A. Dádiva e associação. In: MARTINS, P. H. A dádiva entre os modernos: discussão sobre os fundamentos e as regras do social. Petrópolis: Vozes, 2002. p.191205.

DODIER, N. Agir em diversos mundos. In: CARVALHO, M. do C. B. de (Org.). Teorias da ação em debate. São Paulo: Cortez: FAPESP; Instituto de Estudos Especiais, PUC, 1993. p. 77-109.

ELIAS, N. A sociedade dos indivíduos. Rio de Janeiro: Jorge Zahar, 1994.

- SCOTSON, J. L. Os estabelecidos e os outsiders: sociologia das relacões de poder a partir de uma pequena comunidade. Rio de Janeiro: Jorge Zahar, 2000.

INCRA. Processo administrativo sobre irregularidades. $\mathrm{N}^{\circ}$ 54220.000240/00-95. Porto Alegre, 2001a. (Arquivado na sede do INCRA-RS).

LATOUR, B. Jamais fomos modernos. Rio de Janeiro: Ed. 34, 1994.

MARIANO, R. Pentecostais e a política no Brasil. Comciencia, São Paulo, Disponível em: 13 mar., 2005 www.comciencia.br/reportagens/2005/05/13. Acesso em: 12 out., 2005.

MARTINS, J. de S. O sujeito oculto: ordem e transgressão na reforma agrária. Porto Alegre: Ed. UFRGS, 2003.

MELLO, P. F. Evasão e rotatividade em assentamentos rurais no Rio Grande do Sul. 2006. Dissertação (Mestrado em Desenvolvimento Rural) - Faculdade de Ciências Econômicas, Universidade Federal do Rio Grande do Sul. Porto Alegre, 2006
POLANYI, K. A grande transformação: as origens da nossa época. 3.ed. Rio de Janeiro: Ed. Campus, 2000.

SABOURIN, E. Dádiva e reciprocidade nas sociedades rurais contemporâneas. Tomo, São Cristóvão, SE, n. 7, p. $75-104,2004$

Práticas sociais, políticas públicas e valores humanos. In: COLOQUIO AGRICULTURA FAMILIAR E DESENVOLVIMENTO RURAL, 1, Porto Alegre, 2005. Anais... Porto Alegre: GEPAD, 2005. CD-Rom.

SANCHIS, P. A contribuicão de Émile Durkheim. In TEIXEIRA, F. (Org.). Sociologia da religião: enfoques teóricos. Petrópolis: Vozes, 2003. p. 36-66.

SILVEIRA, C. B. da. Organizações e a "lei de ferro das oligarquias": um estudo sobre os assentamentos rurais de reforma agrária. 2003. Dissertação (Mestrado em Desenvolvimento Rural) - Programa de Pós-Graduação em Desenvolvimento Rural, Faculdade de Ciências Econômicas, Universidade Federal do Rio Grande do Sul, Porto Alegre, 2003. Disponível em: www.ufrgs.br/pgdr. Acesso em: 10 nov., 2004.

WOLF, E. R. Sociedades camponesas. São Paulo: Zahar Editores, 1976.

Comunidades camponesas corporadas fechadas na Mesoamérica e em Java Central. In: FELDMANBIANCO, B.; RIBEIRO, G. L. (Org.). Antropologia e poder. Brasília: UNB, 2003. p. 145-164.

WOORTMANN, E. F. Herdeiros, parentes e compadres: colonos do sul e sitiantes do Nordeste. São Paulo: Hucitec; Brasília: Edunb, 1995. 


\section{SOCIAL COHESION AND RURAL EVASION IN RURAL ENCAMPMENTS IN THE SOUTH OF BRAZIL}

\author{
Paulo Freire Mello
}

Through ethnographies in two encampments in Rio Grande do Sul, the processes of social cohesion and its potentiality in stanching the escape and the rotation in rural areas are discussed. No correlation was found between rural evasion and several variables related to the material dimension in 193 encampments. The adoption of the sociological perspective of the Boltanski critics, in association with punctual contributions of Bourdieu, Wolf and Elias, allowed to understand the mobility and construction of the social cohesion processes of those encamped. The latter is related to reciprocity, especially to kinship and the religious and neighborhood relations. It was verified that the encamped, more and more located in the domestic city, they are building corporate processes, even if in a negotiated way with MST, INCRA and neighborhood.

KEYWORDS: rotation, land reform, reciprocity, sociology of the critic, religion.

\section{LA COHÉSION SOCIALE ET L'ÉVASION VERS LES ASSENTAMENTOS RURAUX DANS L'EXTREME SUD DU BRESIL}

\author{
Paulo Freire Mello
}

Ce sont des ethnographies faites dans deux assentamentos du Rio Grande du Sud qui nous ont permis de discuter des processus de cohésion sociale et de leur potentiel pour arrêter l'évasion et le roulement. Aucune corrélation entre l'évasion et les diverses variables liées à une dimension matérielle n'a pu être établie au sein de 193 assentamentos étudiés. Grâce à l'adoption de la perspective de la sociologie critique de Boltanski, associée à des apports ponctuels de Bourdieu, Wolf et Elias, nous avons pu comprendre les processus de mobilité et de construction de la cohésion sociale des personnes concernées par les assentamentos. Cette cohésion est liée à la réciprocité, tout particulièrement en ce qui concerne les liens de parenté et les rapports religieux ainsi que ceux de bon voisinage. Nous avons pu vérifier que les personnes des assentamentos, chaque fois plus proches de la ville domestique, sont en train de construire des processus corporatifs, souvent sur la base d'une négociation avec le MST, l'INCRA et leurs voisins.

Mots-CLÉs: roulement, réforme agraire, réciprocité, sociologie critique, religion.

Paulo Freire Mello - Doutorando do Programa de Pós Graduação em Desenvolvimento Rural da Universidade Federal do Rio Grande do Sul. É Engenheiro Agrônomo e mestre em desenvolvimento Rural pela mesma Universidade. Tem experiência na área de Antropologia, Sociologia e sistemas de produção, atuando no tema reforma agrária, sobretudo com assentamentos rurais. Em 2006, defendeu a dissertação de mestrado: Evasão e rotatividade em assentamentos rurais do Rio Grande do Sul. Vem, desde 2005, publicando artigos sobre assentamentos em suas dimensões sociológica-antropológica, econômica e agronômica. 